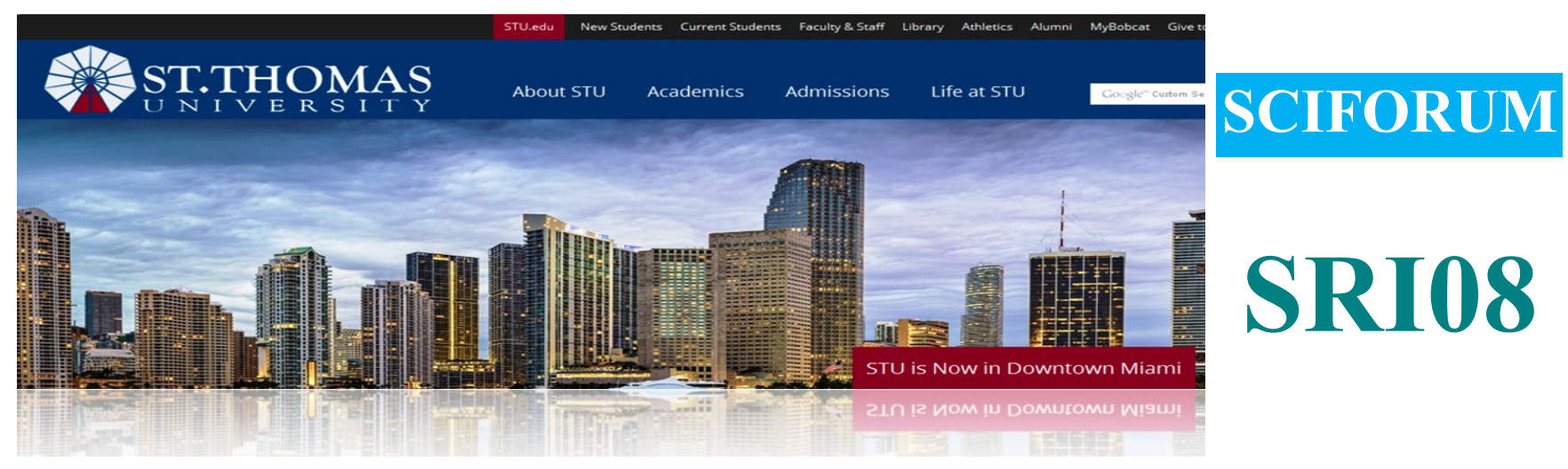

\title{
SRI-08: The 8th Annual Undergraduate Summer Research Symposium of Saint Thomas University.
}

David Quezada, Email: dquesada@stu.edu

Saint Thomas University (STU), Carnival Building, Room 115, Miami, FL, USA.

Humberto González-Díaz, Email: humberto.gonzalezdiaz@ehu.eus

(1) Department of Organic Chemistry II, University of Basque Country (UPV/EHU), Biscay, Spain.

(2) IKERBASQUE, Basque Foundation for Science, Bilbao, Biscay, Basque Country, Spain.

\begin{abstract}
Dear colleagues we welcome you to the symposium of the Summer Research Institute (SRI) with Head Quarters (HQ) at Saint Thomas University (STU), and supported by Miami Dade College (MDC), Miami, Downtown, FL, USA . This is face-to-face (in person) workshop associated to and hosted online by MOL2NET-2, International Conference of Multidisciplinary Sciences, 2016, MDPI, Sciforum, Basel, Switzerland, with HQs, University of The Basque Country (UPV/EHU), and supported by IKERBASQUE, Basque Foundation for Science, Basque Country, Bilbao, Spain.
\end{abstract}

\section{Welcome Message}

Eight years have passed since the First Annual Undergraduate Summer Research Symposium. Over this period of time, the School of Science, Technology, and Engineering Management of Saint Thomas University (STU) in partnership with Miami Dade College (MDC) and with the continuous support of the faculty and staff has provided an excellent internship program to our students and those coming from our partner's institutions. From the start the Carnival Cruise Lines Science and Technology Building focused on the hands-on research experience. This places our students in an excellent position to gain entrance into graduate, or professional Schools, or to directly enter the workforce in South Florida. Most students in other institutions do not have this research opportunity until they reach graduate school.

The faculty and staff of the School of Science are committed to providing a quality education in the sciences and offer the unique opportunity to talented undergraduate students, to experience hands-on research in ten research laboratories alongside their professors. In addition, the Summer Research Institute (SRI) has enhanced the instrumentation capacity of our institution. Such improvements have allowed deepening our research projects as well as to establish new alliances in research and 
development. Results from our projects already circulate in local, national and international conferences, augmenting this way the visibility of the institution and the pride that students might have for their faculty and work accomplished. The eight edition of the SRI offered a continuous lecture series "Moving into the Future" on a weekly basis. Ten speakers from University of Miami, Florida International University, and local Technological companies came to St. Thomas to share their wisdom as an in kind contribution.

This year, the memories of the Annual Symposium will be published online in the open source forum MOL2NET of Sciforum platform. All presentations will be peer reviewed and a DOI number will be assigned. MOL2NET conference of Sciforum is one of the platforms internationally recognized for scientific exchange. This annual edition is full of diversity in topics, approaches, and integration of disciplines, representing one of the common paradigms of modern science, inter-disciplinarity, teamwork and networking. I hope you will enjoy the program and the presentations.

Special thanks to our sponsors, Miami Dade College, STEM-TRAC grant, St. Thomas School of Science, Technology, and Engineering Management, Yager Foundation, Monet Coiffure, In Fashion Forever, and Physics \& Mathematics Solutions, who provided funding for major and minor activities associated with the 2016 edition. Follow the link to download and/or read the full program [SRI08 Programl

\section{Program Overview}

8:00 - 9:00 Registration and Poster Setup. Judges meet in room CCL 111

9:00 - 9:05 Invocation by Rev. Alfred Cioffi

9:05 - 9:20 Opening Comments by Dr. Adrienne Vynne, Dean of School of STEM

9:20 - 9:35 Opening Comments by Dr. Irma Becerra, Provost of St. Thomas

University

9:35 - 9:45 Session Introduction by Dr. David Quesada, Coordinator SRI 2016

9:45 - 10:00 Oral Presentation 1

10:00 - 10:15 Oral Presentation 2

10:15 - 10:30 Oral Presentation 3

10:30 - 10:55 Break

11:00 - 11:15 Oral Presentation 4

11:15 - 11:30 Oral Presentation 5

11:30 - 11:45 Oral Presentation 6

12:00 - 13:00 Lunch Break courtesy of the School of STEM

13:00 - 15:00 Poster Session

15:00 - 15:30 Judges meet in CCL 111 to choose the awards

15:30 - 15:45 Announcement of Awards

\section{Submission Notes}

This workshop is planned to be held on Sept, 2016. However, the submission is open and the publication of communications will be ASAP after acceptance, all the year. To submit a communication use the Submission link. After you successfully register, you can submit your paper online. You need to register and send your abstract first. After abstract approval you need to send your communication. Firstly, you need to submit only the title, authors, and short abstract. Secondly, you could submit your full work in .doc and .pdf format after receiving the approval email from the chairperson. Please, download and use the following .doc file as [SRI08 2016 Official Template] to submit your work. For more details contact the Chairman of the workshop. 
Be aware:

on step 1, you should select MOL2NET 2016, International Conference on Multidisciplinary Sciences, 2nd edition (Conference),

on step 2, you should select SRI08: Saint Thomas University Research Experience for Undergraduates, Miami, 2016.

\section{Author Contributions}

SRI08 Chairperson: Prof. David Quezada, Associate Professor of Physics, Email: dquesada@stu.edu Saint Thomas University (STU), Carnival Building, Room 115, Miami, FL, USA. (MOL2NET Honor Committee)

Publication Advisory Chair: Prof. Humberto González-Díaz, IKERBASQUE Prof., Ph.D., Email: humberto.gonzalezdiaz@ehu.eus

(1) Department of Organic Chemistry II, University of Basque Country (UPV/EHU), Campus Bizkaia, Basque Country, Spain.

(2) IKERBASQUE, Basque Foundation for Science, Bilbao, Bizkaia, Basque Country, Spain. (MOL2NET Conference Chairman).

Symposium Committee: follow the link to see the full symposium committee, please take into consideration that the committee list may change upon final completion. http://sciforum.net/conference/mol2net-02/sri-08 